\title{
Diálogos possíveis entre o Supremo Tribunal Federal e a Corte Interamericana de Direitos Humanos no "Caso Araguaia": uma defesa ampla, geral e irrestrita dos direitos humanos?
}

Possible dialogues between Brazilian Supreme Court and the Interamerican Human Rights Court about "Araguaia Case": a broad, general and non-restrictive defense of Human Rights?

\section{Fauzi Hassan Choukr}

Pós-Doutor em Democracia e Direitos Humanos pela Universidade de Coimbra; Doutor e Mestre pela Universidade de São Paulo. Promotor de Justiça no Estado de São Paulo.

fhchoukr@uol.com.br

Resumo: O texto busca oferecer alternativas de interpretação na tarefa de conciliar a leitura de direito interno e aquela da Corte Americana de Direitos Humanos sobre a denominada "lei da anistia" que impossibilita, até o presente momento, a persecução penal dos crimes cometidos no regime militar que vai de 1964 a 1985 . Tenta-se, assim, conferir eficácia aos compromissos internacionais assumidos pelo Brasil a fim de que não venham a ser desprezados na consolidação da democracia brasileira.

Palavras-chave: Direitos Humanos; Corte Intermaricana; Lei de anistia.

ResUME: This paper tries to offer alternatives in order to conciliate the interpretations given to the "amnesty law" by Brazilian Supreme Court and the Interamerican Human Rights Court, law on whose behalf can not be possible, until now, enforcing criminal prosecutions against those who alleged had commited crimes during the years 1964-1985 when Brazil was ruled by the militaries. This is an attempt to give full effectiveness to the internacional compromises assumed by the Brazilian State and that must be understood as essentials for the consolidation of Brazilian democracy.

KEYWORDs: Human rights; Interamerican court; amnesty law. 


\section{INTRODUÇÃO}

O Estado brasileiro, pela via jurisdicional, vem sendo chamado a construir uma resposta às violências praticadas ao longo do regime militar compreendido entre 1964 e 1985. Impulsionado mais por fatores políticos externos do que por interpretações jurídicas típicas de um ambiente processual propriamente, o Supremo Tribunal Federal (STF) deparou-se com a provocação de um mecanismo de controle de constitucionalidade que lhe exigiu uma tomada de posição sobre o quanto se convencionou, quase que a titulo de senso comum, denominar de "lei da anistia".

Com algo de surpreendente no ajuizamento dessa "arguição" se tomado o silencio social que permeou o assunto desde a reconstrução formal democrática até o momento em que o tema ganhou espaço em alguns setores sociais, o STF deparou-se não apenas com um julgamento técnico interno mas, também, e pouco tempo depois, com a necessidade de relacionar-se com o julgamento da Corte Interamericana de Direitos Humanos (CADH) sobre um dos episódios mais notórios daquela quadra histórica de exceção, o denominado "caso Araguaia".

Anistia consolidada no direito interno, censurada foi no âmbito internacional na esteira do quanto, em casos semelhantes, já havia se posicionado aquela Corte de direitos humanos. Choque que coloca em polos opostos interpretações e, por que não dizer, interações, nascidas de compromissos de um Estado (mais uma vez) recém democratizado - o brasileiro - com um contexto internacional amplo, geral e irrestrito, para usar-se o jargão vigente no auge do estado militar acerca da anistia - em defesa dos direitos humanos e da persecução dos perpetradores dessas violências.

O texto que segue é uma tentativa de buscar um plano de convivência entre as esferas nacional e internacional incrementando, assim, os fundamentos de sustentabilidade democrática que permitem a convivência com o passado na construção do presente e futuros democráticos. 


\section{O PAPEL DA ANISTIA POLÍTICA-JURÍDICA}

De todo o cenário atrás apontado destaca-se para a compreensão do sistema formal de solução de conflitos em relação aos fatos passados ${ }^{1}$ o período dentro do qual, em 1979, deu-se a anistia "ampla, geral e irrestrita”, regulada que foi pela Lei de Anistia, que valia para todos os casos que ainda não estivessem sub judice, a dizer, a maioria dos feitos criminalmente puníveis, sobretudo no que tange à violência oficial produzida pelo Estado.

Cumpre cifrar que durante o governo Geisel, houve uma "semi-anistia", mas necessariamente a dada em 1979 é que se tornou o cerne de todas as questões que envolvem a punição e o perdão dos militares enquanto governo. $\mathrm{O}$ movimento pró-anistia insurgiu-se contra a Lei e contra o Decreto que a regulamentou ${ }^{2}$, pois tencionava que os responsáveis pelo desaparecimento de 197 presos políticos viessem a ser chamados para responder por esses atos.

Todavia, as dúvidas parecem ter sido solucionadas pela inteleç̧ão forçada da redação e pelos limites impostos pela própria lei de anistia, assim determinando em seu artigo $1^{\mathrm{o} 3}$. A cobertura a ser dada aos militares estava no disposto no $\S 1^{\circ}$, desse mesmo artigo, assim considerado: $\S 1^{\circ}$. Consideram-se conexos, para efeito desse artigo, os

1 Com uma sentida ausência do Poder Judiciário naquele momento como apontado por vários autores, entre eles Oliveira Fabiana Luci de. O Supremo Tribunal Federal no processo de transição democrática: uma análise de conteúdo dos jornais Folha De S. Paulo e O Estado De S. Paulo. Rev. Sociol. Polít., Curitiba, 22, p. 101-118, jun. 2004.

2 Mesmo a Ordem dos Advogados do Brasil ao oferecer parecer sobre a lei da anistia deixava antever, diante da redação ambígua daquele documento, a insatisfação pela impunidade dos agentes estatais envolvidos nas violências noticiadas. O parecer pode ser consultado em http://s.conjur.com.br/dl/parecer_oab_anistia_79.pdf

3 Da Lei no 6.683, de 28 de Agosto de 1979. Este artigo está repetido no Decreto no 84.143, de 31 de Outubro de 1979, que regulamenta a indigitada lei. Observações: 02 de Setembro de 1961 foi a data da última anistia concedida. O tema viria a ser retomado três décadas mais tarde com a ADPF 153 como adiante se verá. 
crimes de qualquer natureza relacionados com crimes políticos ou praticados por motivação política.

Portanto, não obstante os militares terem cometidos crimes comuns capitulados na Legislação Penal, tais crimes, quando cometidos, tinham sempre uma justificação política, o que acobertava a maioria dos torturadores, apesar das restrições à "atentados pessoais" constantes no parágrafo subsequente ${ }^{4}$, que exigia condenação anterior já transitada em julgado. Pesa contra, ainda, que todas as atrocidades perpetradas durante o regime militar tinham por baliza ideológica e doutrinária os preceitos de investigação inquisitorial contidas no corpo da Lei de Segurança Nacional (Decreto-Lei no 898/69), que em seus artigos $1^{\circ}$ a $7^{\circ}$, consagravam o que estava doutrinariamente por trás da atividade desenvolvida nos "porões da ditadura".

Mas "aqui, a oposição tocava em um nervo exposto - o medo dos militares de que uma investigação judicial algum dia tentasse fixar responsabilidades pela tortura e morte de prisioneiros" e evidenciava o quanto a extensão da anistia aos militares foi um importante mecanismo de assegurar a estabilidade política para a reconstrução democrática ${ }^{5}$.

Pelas razões expostas compreende-se porque, no caso brasileiro, não se cogitou no conceito de "delinquência do Estado" como um conceito jurídico reconhecido oficialmente de modo a empregar o sistema penal como mecanismo de sanção. No sentido penal não haveria de existir criminosos, tampouco vítimas de crimes. Isto muda toda a forma política, social e jurídica do enfrentamento da matéria e, como efeito colateral, perpetua as violências institucionais e estabelece o silêncio como sinônimo - ou condicionante - da paz dado que o processo de transição política contou com domínio quase absoluto dos então detentores do poder.

4 Reza o §2o: "Excetuam-se dos benefícios da anistia os que foram condenados pela prática de crimes de terrorismo, assalto, seqüestro, e atentado pessoal"

5 Neste sentido, LEMOS, Renato. Anistia e crise política no Brasil pós-1964. Topoi, Rio de Janeiro, n. 5, p. 287-313, set. 2002. Ainda, em complementação, GABEIRA, Fernando. Carta sobre a anistia: a entrevista do Pasquim. Rio de Janeiro,: Codecri, 1979. 
Instigar o funcionamento da máquina judicial penal para análise dos crimes ocorridos acarretaria, segundo inúmeras leituras da época e mesmo por longo tempo depois, a inviabilização do processo de superação do regime militar, não havendo, sugestivamente, "condições políticas" para que houvesse uma estrita apuração dos crimes e a devolução do poder à sociedade civil. ${ }^{6}$

Acompanhava-se, assim, uma visão que foi inicialmente predominante em países de certa comunhão histórica, política e econômica como Argentina, Chile, Uruguai, Paraguai e Peru onde o mecanismo da anistia serviu como escudo jurídico para a impunidade dos fatos do período precedente entendendo-se, aqui, as violências de Estado. A superação do emprego desse mecanismo ainda demandaria tensa e longa maturação. ${ }^{7}$

As consequências são impressionantes para a sociedade brasileira. Este processo de transição sedimentou culturas sociais intimamente ligadas à violência institucional em praticamente todos os setores da sociedade brasileira. Estritamente no plano judiciário penal conceitos e práticas vividos no seio do regime de exceção são vivenciados ainda hoje.

\section{O REENCONTRO COM O PASSADO}

A superação do regime de exceção, ao menos em seu aspecto formal, não se fez acompanhar, de imediato, da criação de mecanismos de enfrentamento da realidade vivida. Das várias razões para esse hiato que podem ser identificadas no amplo tecido social, uma de ordem política (o processo de impeachment do então Presidente Fernando Collor

6 Neste sentido uma abordagem de complementariedade ao processo de transição, interagindo os interesses das denominadas "elites" nacionais e, de outro lado, pressões de segmentos sociais em DINIZ, Eli. A transição política no Brasil. Uma reavaliação da dinâmica da Abertura. Dados, Rio de Janeiro, v. 28, n. 3, p. 329-346, 1985.

7 Numa vasta bibliografia acerca do assunto veja-se, inicialmente, Mallinder, Louise. "Amnesties' Challenge to the Global Accountability Norm? Interpreting Regional and International Trends in Amnesty Enactment." (2012): 69-96. 
de Mello, em 1992) e outra, de ordem econômica (a crônica desestabilidade da economia brasileira exemplificada nos escorchantes índices inflacionários vividos até 1994), são possivelmente as mais sentidas. Essas condicionantes desestimularam a discussão profunda do papel da anistia concedida e seus reflexos na sociedade brasileira e, de forma mais ampla, foram responsáveis pela carência de discussão mais consistente do momento histórico anterior como um todo.

Não por outro motivo os primeiros mecanismos de diálogo com o passado foram as indenizações civis ${ }^{8}$ estabelecidas ainda no primeiro governo do presidente Fernando Henrique Cardoso, e como parte do Programa Nacional de Direitos Humanos quando foi editada a Lei $N^{\circ}$ 9.140, De 04 De Dezembro De 1995, que reconhece como mortas pessoas desaparecidas em razão de participação, ou acusação de participação, em atividades políticas, no período de 2 de setembro de 1961 a 15 de agosto de 1979. (art. $1^{\circ}$ )

É da mesma Lei 10559 de 13 de novembro de 2002 a recomposição, por vias administrativas, das condições da vida civil das pessoas perseguidas pelo regime militar, seja assegurando seu estado jurídico de anistiado político, seja com o reconhecimento de direitos previdenciários.

$\mathrm{O}$ incremento da memoria como mecanismo indispensável para superação do período de exceção, instrumento recorrente no cenário internacional ${ }^{9}$, igualmente tardou a ganhar folego na sociedade brasileira e mesmo no meio jurídico que apenas recentemente aden-

8 Para uma ampla visão sobre esse mecanismo consulte-se MEZAROBBA, Glenda. $\mathrm{O}$ preço do esquecimento: as reparações pagas às vítimas do regime militar (uma comparação entre Brasil, Argentina e Chile). Tese. Faculdade de Filosofia, Letras e Ciências Humanas, Universidade de São Paulo (USP). São Paulo, 2008.

9 Veja-se, a respeito, Bal, Mieke, Jonathan Crewe, and Leo Spitzer, eds. 1999. Acts of Memory: Cultural Recall in the Present. Hanover, NH: University Press of New England. Ainda: Barahona de Brito, Alexandra, Carmen González-Enríquez, and Paloma Aguilar, eds. 2001. The Politics of Memory: Transitional Justice in Democratizing Societies. New York, NY: Oxford University Press; Barthel, Diane L. 1996. Historic Preservation: Collective Memory and Historical Identity. New Brunswick, NJ: Rutgers University Press. 
sou a compreensão de ser o direito à memória um verdadeiro direito fundamental ${ }^{10}$ que deve ser difundido, inclusive, com o emprego de tecnologias de educação de massa ${ }^{11}$ e apto a ser exigível por meio de políticas públicas judicialmente reconhecíveis ${ }^{12}$

Neste aspecto, a obra Direito à memória e à verdade patrocinada pelo Governo Federal teve sua primeira edição em $2007^{13}$ ou seja, 22 anos após a saída dos militares do poder, ocasião em que, talvez de forma pioneira no âmbito governamental, foi empregada a expressão "terror de Estado" 14 e sustentava a necessidade de ser apresentada, pelos militares, de forma transparente, a verdade sobre os fatos ocorridos. No mesmo cenário político e cultivada pelo "Movimento Nacional de Direitos Humanos" outras obras caminharam no sentido do incremento da memória como condicionante da sustentabilidade democrática ${ }^{15}$

Posteriormente, o III Plano Nacional de Direitos Humanos estabeleceu na "Diretriz 23" o reconhecimento da memória e da verdade

${ }^{10}$ Leal Rogério Gesta. A Memória Como Direito Fundamental Civil E Político: Qual O Caminho Brasileiro? In Verdade, memória e justiça [recurso eletrônico]: um debate necessário/ Rogério Gesta Leal organizador. - Santa Cruz do Sul: EDUNISC, 2012.. páginas 08/34.

11 BATISTA, C. K. L.; GITAHY, R. R. C. . O direito à memória e à verdade e sua difusão virtual: tecnologia e saberes sociais aliados na preservação da história. In: Alessandro Martins Prado; Claudia Karina Ladeia Batista; Isael Jose Santana. (Org.). Direito à Memória e à Verdade e Justiça de Transição no Brasil: uma história inacabada! Uma República Inacabada. 1ed.Curitiba: CRV, 2011, v. 1, p. 89-100.

12 LEMOS, Maitê Damé Teixeira.; LEAL, M. C. H. . O controle jurisdicional de políticas públicas no âmbito da verdade, justiça e reconciliação: um caminho entre o ativismo e a efetiva proteção dos direitos humanos. In: Rogério Gesta Leal. (Org.). Verdade, memória e justiça: um debate necessário. 1ed. Santa Cruz do Sul: EDUNISC, 2012, v., p. 35-58

13 Íntegra disponível em http://www.sedh.gov.br/clientes/sedh/sedh/bibliote$\mathrm{ca} /$ serie-direito-a-memoria-e-a-verdade

14 Op. Cit, Pg. 27

15 Veja-se "Uma História por contar...Pelo direito humano à memória e à verdade no Brasil", disponível na integra em http://www.dhnet.org.br/dados/ campanhas/a_pdf/mndh_cartilha_hist_contar.pdf 
como Direito Humano da cidadania e dever do Estado ${ }^{16}$ cujo objetivo estratégico é o de "promover a apuração e o esclarecimento público das violações de Direitos Humanos praticadas no contexto da repressão política ocorrida no Brasil no período fixado pelo artigo $8^{\circ}$ do ADCT da Constituição, a fim de efetivar o direito à memória e à verdade histórica e promover a reconciliação nacional" cuja "ação programática" mais aguda e fecunda foi a de criar o espaço jurídico e político para o estabelecimento da "Comissão Nacional da Verdade, composta de forma plural e suprapartidária, com mandato e prazo definidos, para examinar as violações de Direitos Humanos praticadas no contexto da repressão política no período mencionado".

Nessa esteira de proposições, em tempos mais recentes iniciativas de várias ordens aconteceram de modo a incrementar a efetivação do direito à memória ${ }^{17}$ mas sérias lacunas ainda podem ser sentidas, como a dificuldade de adaptação de materiais didáticos no ensino fundamental ${ }^{18}$

${ }^{16}$ A respeito, OLIVEIRA, A. J.; LIMA, A. D.; Prado, A.L.; Silva, E.M.M.; Aonso, A.M.O.; Batista, C.K.L.; GITAHY, R. R. C.; ARAUJO, D. A. C.; Araújo, E.L. . Memória E Verdade Com Um Direito Absoluto E Inalienável Independentemente Das Forças Do Poder.. In: Alessandro Martins do Prado; Cláudia Karina Ladeia Batista; Isael José Santana. (Org.). Direito à memória e à verdade e justça de transição no Brasil Uma história inacabada! Uma República inacabada. 1ed.Curitiba-PR: CRV, 2011, v., p. 43-54.

17 Veja-se Direito à memória e à verdade: seminário [recurso eletrônico]. Brasília: Câmara dos Deputados, Edições Câmara, 2012. 166 p. - (Série ação parlamentar; n. 433) Seminário realizado pela Comissão de Direitos Humanos e Minorias da Câmara dos Deputados em 2009. ISBN 978-85736-5953-5

18 Sobre esse assunto, REis, Thiago Felipe dos e Prado, ELIANE Mimesse. Entre a teoria e a prática: a ditadura militar brasileira em manuais didáticos da educação básica Anais Eletrônicos do IX Encontro Nacional dos Pesquisadores do Ensino de História 18, 19 e 20 de abril de 2011Florianópolis/SC . In: IX Encontro Nacional dos pesquisadores do Ensino de História: América latina em perspectiva: culturas, memórias e saberes, 2011, Florianópolis. Caderno de Resumos. Florianópolis: Imprensa Universitária, 2011. v. 1. p. 97. Para uma abordagem do assunto no cenário internacional Cole, Elizabeth A. 2007. Transitional 
que contemplem com mais clareza e isenção os episódios passados ${ }^{19}$ e, nas escolas militares, a permanência de visões parciais e não suscetíveis da necessária revisão. ${ }^{20}$

\section{O APROFUNDAMENTO DA TRANSIÇÃO E A AMPLIAÇÃo DA DISCUSSÃO}

Em 24 de agosto de 2001, foi criada, pela Medida Provisória no 2151-3, a Comissão de Anistia do Ministério da Justiça ainda no segundo governo Fernando Henrique Cardoso, norma proveniente da outra Medida Provisória, a de $n^{\circ}$ 65, de 28 de agosto de 2002 finalmente convertida na Lei no 10.559 , de 13 de novembro de $2002 .{ }^{21}$

Foi a partir dessa base normativa que a Comissão da Anistia, juntamente com o Ministério da Justiça, em julho de 2008, já então no governo do ex-Presidente Luis Inácio Lula da Silva promoveram audiência pública sobre "Limites e Possibilidades para a Responsabilização Jurídica dos Agentes Violadores de Direitos Humanos durante o Estado de Exceção no Brasil", que discutiu a interpretação da Lei de Anistia de 1979 no que se refere à controvérsia jurídica e política envolvendo a prescrição ou imprescritibilidade dos crimes de tortura.

Abria-se a porta, assim, para pautar na agenda social como um todo, e na jurídica, em particular, o tema da anistia, instrumento nodal, como já visto, na transição liberalizante brasileira.

Justice and the Reform of History Education. International Journal of Transitional Justice 1 (1):115-137.

19 Também acerca do assunto P1Azza, Rosimary e PRIORI Angelo. O ensino de história durante a ditadura militar. II Encontro de Pesquisa em Educação, 2007, Maringá. Anais do II Encontro de Pesquisa em Educação.. Maringá: UEM-DTP, 2007.v. 1.p. 1-9.

20 A esse respeito, http://observatoriodedefesa.blogspot.com.br/2013/02/material-didatico-de-escolas-militares.html.

${ }^{21}$ Essas normas visavam regulamentar o Art. $8^{\circ}$ do Ato das Disposições Constitucionais Transitórias (ADCT) da Constituição de 1988, que previa a concessão de anistia aos que foram perseguidos em decorrência de sua oposição política e constituíram o passo mais avançado até então no resgate dos fatos ocorridos no estado de exceção 


\section{O SISTEMA PENAL INSTADO A ATUAR}

\subsection{A REVISÃo DA ANISTIA}

Rever a anistia no cenário jurídico brasileiro é amplamente mais complexo do que simplesmente apontar suas consequências sociais e discutir seu funcionalidade no momento histórico em que ela se deu e, mesmo, apontar no âmbito de outras áreas do conhecimento sua (im) pertinência na atual realidade brasileira aqui considerada de uma maneira holística. ${ }^{22}$

Normalmente análises externas à técnica jurídica empregam situações históricas sem a devida precisão conceitual e, dessa premissa surgem argumentos jurídicos insustentáveis como quando se afirma que "Uma das questões mais delicadas para transição brasileira, a exemplo de outros países, foi o tratamento a ser dado aos agentes do Estado que praticaram açóes tipificadas, já nessa época, como crimes contra a bumanidade" (sem grifo no original) referindo-se, em nota de rodapé, ao texto da Declaração Universal dos Direitos Humanos, ONU, 1947. ${ }^{23}$

Sob o aspecto legal não apenas é amplamente discutível a força normativa de "Declarações" perante o direito interno como é inviável tal argumento perante a estrutura basilar do Direito Penal no estado de direito, regido pela legalidade estrita e dotado da irretroatividade normativa "in malam partem".

Analisada contemporaneamente e, na maioria das vezes de forma pejorativa, a anistia passou a ser considerada como o grande mecanismo a ser desconstituído. Para tanto a assunção, pelo Brasil, de compromissos internacionais protetivos de direitos humanos serve como arrimo argumentativa essencial.

22 Tema, aliás, obviamente não restrito ao Brasil. A discussão sobre essa (im) pertinência conta com literatura trasndisciplinar (e interdisciplinar) vastissima como, por exemplo, Huyse, Luc. 2001. "Amnesty, Truth, or Prosecution?” In Reychler, Luc and Thania Paffenholz, Peace-building: A Field Guide. Boulder, CO: Lynne Rienner Publishers.

23 A propósito, D'ARAUJO, Maria Celina Soares . O estável poder de veto Forças Armadas sobre o tema da anistia política no Brasil. Varia História (UFMG. Impresso), v. 28, p. 573-597, 2012 o 


\subsubsection{OS COMPROMISSOS INTERNACIONAIS}

As condições políticas após o fim da Guerra Fria propiciaram o surgimento de uma fase de expansão de compromissos internacionais voltados para a proteção dos "direitos humanos" que, malgrado a polissemia que lhes cerca não se trata, reduzidamente, de uma noção "confusa, ilusória" e, possivelmente, "efeito de uma incultura, e de uma regressão da ciência jurídica" ${ }^{24}$.

Mesmo porque, em nome dessa "incultura" vidas humanas são valorizadas e se tenta (re)construir, também no âmbito judiciário ${ }^{25}$, uma rede de mecanismos que vai muito além daquela estabelecida no período anterior ao da própria criação do tecido internacional que uniria nações em torno de uma organização, malgrado as condições políticas peculiares a cada situação possam servir, ainda, de freio à plena efetividade desses direitos ${ }^{26}$

Melhor, portanto, acompanhar Bobbio ao se referir ao marco inicial dessa "incultura", a dizer, a Declaração Universal quando afirma que

Com essa declaração, um sistema de valores é - pela primeira vez na história - universal, não em princípio, mas de fato, na medida em que o consenso sobre sua validade e sua capacidade para reger os destinos da comunidade futura de todos os homens foi explicitamente declarado. (...) Somente depois da Declaração Universal é que podemos ter a certeza histórica de que a humanidade - toda a humanidade - partilha alguns valores comuns; e podemos, finalmente, crer na universalidade dos valores, no único sentido em que tal crença é historicamente legítima, ou seja, no sentido em que universal

${ }^{24}$ E esse é somente o inicio da critica. VILLEY, Michel. O direito e os direitos humanos. SP: Martins Fontes, 2007.p. 17

25 A propósito,_Lutz, Ellen e Kathryn Sikkink. 2001. The Justice Cascade: The Evolution and Impact of Foreign Human Rights Trials in Latin America. Chicago Journal of International Law 2 (1):1-34.

26 Ratner, Steven R. and Jason S. Abrams. 1997. Accountability for Human Rights Atrocities in International Law: Beyond the Nuremberg Legacy. New York: Oxford University Press. 
significa não algo dado objetivamente, mas subjetivamente acolhido pelo universo dos homens. ${ }^{27}$

Observados os compromissos assumidos pelo Brasil a partir de 1988, notadamente a partir do quanto consta no artigo Art. $4^{\circ} \mathrm{da}$ Constituição que prevê que "A República Federativa do Brasil rege-se nas suas relações internacionais pelos seguintes princípios: ... II - prevalência dos direitos humanos" passou-se, com o III Plano Nacional de Direitos Humanos já mencionado, ao aprofundamento das discussões sobre a lei de anistia, agora em nome dos primados que animam a República brasileira nos relacionamentos internacionais.

Acompanhando intensa literatura que aponta a impunidade decorrente da anistia ${ }^{28}$, a incisiva história de superação desse mecanismo em países vizinhos, notadamente Argentina ${ }^{29}$, Chile $^{30}$ e Uruguai ${ }^{31}$,

27 BOBBIO, Norberto. A era dos direitos. Rio de Janeiro: Campus, 1992. p. 28

Dentre outros títulos: Roht-Arriaza, Naomi, (Ed.). 1995. Impunity and Human Rights in International Law and Practice. New York: Oxford University Press. Ainda: Chigara, Ben. 2002. Amnesty in International Law: The Legality under International Law of National Amnesty Laws. Harlow, UK: Longman e Mallinder, Louise. 2008. Amnesty, Human Rights and Political Transitions: Bridging the Peace and Justice Divide. Oxford, UK: Hart Publishing.

29 A vasta litetura do caso argentino pode ser aqui exemplificada com HELMKE, G., Courts Under Constraints: Judges, Generals, and Presidents in Argentina (Cambridge University Press, 2005); NINO, Carlos Santiago, Radical Evil on Trial (Yale University Press, New Haven 1996); Roehrig, Terence, The Prosecution of Former Military Leaders in Newly Democratic Nations: The Cases of Argentina, Greece, and South Korea (McFarland \& Company Inc Publishers, Jefferson, NC 2002) e, por fim, Bakker, Christine A. E., 'The Full Stop to Amnesty in Argentina: The S_i_m_ón__Case' (2005) 3(5) J Int'L Crim Just 1106

30 A propósito, Barahona de Brito, Alexandra, 'The Pinochet Case and the Changing Boundaries of Democracy' in Davis, Madeleine (ed), The Pinochet Case: Origins, Progress and Implications (Institute of Latin American Studies, London 2003)

31 Para uma visao histórica do regime de exceção nesse país, Servicio Paz y Justicia, Uruguay Nunca Más: Human Rights Violations, 1972-1985 (Temple University Press, Philadelphia 1992) e, para uma abordagem 
a criação do Tribunal Penal Internacional ${ }^{32}$ onde o princípio da jurisdição universal ${ }^{33}$ e da complementariedade ${ }^{34}$ passaram a ser importantes mecanismos na construção argumentativa e normativa da matéria e, ainda, o papel desempenhado pela Corte Interamericana de

da transição e chamada de responsabilidades pelas violências passadas Barahona de Brito, Alexandra, 'The Long and Tortuous Path to Military Amnesty and the Referendum in Uruguay, 1985-1989' in Barahona de Brito, Alexandra (ed), Human Rights and Democratization in Latin America: Uruguay and Chile (Oxford University Press, Oxford 1997) e González González, José Luis and Pablo Galain Palermo, 'Uruguay' in Ambos, Kai, Ezequiel Malarino and Gisela Elsner (eds), Jurisprudencia Latinoamericana Sobre Derecho Penal Internacional (Konrad-AdenauerStiftung, Berlin 2008)

${ }^{32} \mathrm{Na}$ igualmente vasta literatura que aborda o TPI, as anistias e a persecução perante aquela Corte, Meintjes, Garth. 2000. Domestic Amnesties and International Accountability. In International Crimes, Peace, and Human Rights: The Role of the International Criminal Court, edited by D. L. Shelton. Ardsley, NY: Transnational Publishers

33 Jurisdição "universal" que, mesmo sendo alvo de intensos antagonismos academicos (a respeito Eser, Albin. "For universal jurisdiction: against Fletcher's antagonism.”Tulsa L. Rev. 39 (2003): 955.) desempenha um relevante papel nesse context. A respeito, Meintjes, Garth, and Juan E. Méndez. 2000. Reconciling Amnesties with Universal Jurisdiction. International Law FORUM du Droit International 2 (2):76-97e Kamminga, Menno T. 2001. Lessons Learned from the Exercise of Universal Jurisdiction in Respect of Gross Human Rights Offenses. Human Rights Quarterly 23 (4):940-974. Para uma perspectiva histórica, Bassiouni, M. Cherif. 2002. Universal Jurisdiction for International Crimes: Historical Perspectives and Contemporary Practice. In Post-Conflict Justice, edited by M. C. Bassiouni. Ardsley, NY: Transnational Publishers.

34 A respeito da relação entre principio da complementariedade e as anistias veja-se DELMAS-MARTY, Mireille. "La responsabilité pénale en échec (prescription, amnistie, immunités).” Antonio Cassese et Mireille Delmas-Marty (éds.), Juridictions nationales et crimes internationaux, PUF (2002): 637.Ainda, DISSENHA, Rui Carlo. “Anistias Como Prática do Direito Internacional Criminal ea Complementaridade do Tribunal Penal Internacional." Revista Brasileira de Direito Internacional-RBDI 1.1 (2006). Sobre complementariedade e soberania, PIOVESAN, Flávia. Princípio da Complementaridade e Soberania. Revista CEJ, Brasília, ${ }^{\circ}$ 11, p. 71-74, 2000. 
Direitos Humanos nesse tema específico ${ }^{35}$ responsável, inclusive, pela mudança de rumos políticos e jurídicos em inúmeros países como os acima mencionados, a Ordem dos Advogados do Brasil aforou perante o Supremo Tribunal Federal (STF) mecanismo criado na nova estrutura constitucional, a denominada "Arguição de Descumprimento de Preceito Fundamental", exigindo que toda a estrutura internacional aderida pelo Brasil realmente tivesse efeitos jurídicos no cenário interno como, aliás, inúmeros segmentos da comunidade internacional assim o defendem ${ }^{36}$.

Assim, o Brasil passou a ser cobrado internamente pelos compromissos internacionais assumidos e, sobretudo, por sua inserção no sistema interamericano de proteção aos direitos humanos, com sua adesão à Declaração, à Convenção e sua submissão à Corte e à Comissão ao lado, por certo, dos demais mecanismos já mencionados.

No mais, o desenvolvimento das relações internacionais construídas pelo Brasil como decorrência da nova estrutura constitucional aponta uma série de compromissos que devem - ou deveriam - se pro-

35 Igualmente vasta é essa bibliografia, que pode ser ilustrada com Lutz, Ellen L., 'Responses to Amnesties by the Inter-American System for the Protection of Human Rights' in Harris, David J. and Stephen Livingstone (eds), The Inter-American System of Human Rights (Clarendon Press, Oxford 1998); Méndez, Juan E. and Javier Mariezcurrena, 'Accountability for Past Human Rights Violations: Contributions of the Inter-American Organs of Protection' (1999) 26(4) Crime \& Soc Just Associates 84; A.A. Cançado Trindade, El Desarrollo del Derecho Internacional de los Derechos Humanos Mediante el Funcionamiento y la Jurisprudencia de la Corte Europea y la Corte Interamericana de Derechos Humanos, CtIADH, San José of Costa Rica, 2007, pp. 1-75; M. Scalabrino, Per Non Dimenticare - Violazioni dei Diritti Umani e Leggi di Amnistia in America Latina, Milano, Vita e Pensiero (V\&P), 2007, pp. 93-145 and 169-213; V.F.D. Cançado Trindade, 'Uma Análise das Leis de Auto-Anistia na Evolução Jurisprudencial da Corte Interamericana de Direitos Humanos', 8 Revista do Instituto Brasileiro de Direitos Humanos (2008) pp. 281-91.

Vinuesa, Raúl Emilio, 'Direct Applicability of Human Rights Conventions within the Internal Legal Order: The Situation in Argentina' in Conforti, Benedetto and Francesco Francioni (eds), Enforcing International Human Rights in Domestic Courts (International Studies in Human Rights, Vol. 49, Martinus Nijhoff Publishers, Hague 1997). 
jetar para o direito interno para além da única efetivamente legislada, a Convenção para a Prevenção e Punição do Crime de Genocídio Ratificada pelo Brasil em 15 de abril de 1952 e transformada na Lei 2889 de 1956.

Com efeito, apenas para ficar no sistema da ONU, até 2008, o Brasil havia se comprometido com a 2) Convenção Internacional sobre a Eliminação de Todas as Formas de Discriminação Racial (1966) (Ratificada pelo Brasil em 27 de março de 1968 e transformada em lei 12.228 de 2010), o Pacto Internacional de Direitos Econômicos, Sociais e Culturais (1966) (O Brasil aderiu ao Pacto em 24 de janeiro de 1992), o Pacto Internacional de Direitos Civis e Políticos (1966) (O Brasil aderiu ao Pacto em 24 de janeiro de 1992), a Convenção sobre a Eliminação de Todas as Formas de Discriminação contra a Mulher (Ratificada pelo Brasil em 1º de Fevereiro 1984 e transformada na Lei 11.343 de 2006) a Emenda ao artigo 20, parágrafo $1^{\circ}$ da Convenção sobre a Eliminação de Todas as Formas de Discriminação contra a Mulher (O Brasil aceitou a emenda em 05 de março de 1997) e o Protocolo Opcional à Convenção sobre a Eliminação de Todas as Formas de Discriminação contra a Mulher (Ratificado pelo Brasil em 28 de Junho de 2002) Convenção contra a Tortura e outros Tratamentos ou Penas Cruéis, Desumanas ou Degradantes (Ratificada pelo Brasil em 28 de setembro de 1989 e transformada em Lei 9455 de 1997) além do Protocolo Opcional à Convenção contra a Tortura e outros Tratamentos ou Penas Cruéis, Desumanas ou Degradantes (Ratificado pelo Brasil em 12 de janeiro de 2007) e a Convenção sobre os Direitos da Criança (Ratificada pelo Brasil em 24 de setembro de 1990), bem como a Emenda ao artigo 43 (2) da Convenção sobre os Direitos da Criança (O Brasil aceitou a emenda em 26 de fevereiro de 1998) e o Protocolo Opcional à Convenção sobre os Direitos da Criança sobre o envolvimento das crianças em conflitos armados (Ratificada pelo Brasil em 27 de janeiro de 2004) e, por fim, a Convenção internacional para a Proteção de Todas as Pessoas contra o Desaparecimento Forçado (Assinada pelo Brasil em 06 de Fevereiro de 2007) ${ }^{37}$, esta última tendo Entrou em vigor em 23 de dezembro de 2010.

37 Fonte: Alto Comissariado dos Direitos Humanos das Nações Unidas, atualizado. 


\subsubsection{As LEITURAS DE DIREITO INTERNO E INTERNACIONAL}

O resultado da apreciação da mencionada ADPF, pelo Supremo Tribunal Federal, pode ser diretamente verificada na lavra do voto do então Ministro Relator, Eros Grau:

a. a lei de anistia é válida e abrange todos os crimes políticos e comuns conexos com os políticos, inclusive os cometidos pelos militares;

b. a lei de anistia é uma lei medida (lei de efeitos concretos) e não pode ser julgada inconstitucional perante a nova ordem;

3. a lei de anistia é anterior à convenção da ONU contra a tortura e outros tratamentos ou penas cruéis, desumanos ou degradantes e à lei brasileira de tortura (Lei 9.455/97) e ao art. 5० XLIII;

4. somente o legislativo teria legitimidade para reformar a lei de anistia;

5. a lei de anistia foi ratificada pela EC 26/85, emenda convocatória da Constituição e que, portanto, integra a nova ordem constitucional. ${ }^{38}$

Para além desses argumentos também foi pontuado que "Se o Tribunal concluir pela constitucionalidade da lei, não surtirá efeitos quanto àqueles que praticaram este ou aquele crime. Se houver a prevalência da divergência e o Tribunal assentar a inconstitucionalidade da norma, o resultado, em termos de concretude ou de afastamento da lesão, quer no campo penal, quer no campo cível, não ocorrerá" 39 e, ainda, "que "Nós sabemos que o prazo maior da prescrição quanto à pretensão da persecução criminal é de 20 anos. Já o prazo maior quanto à indenização no campo cível é de 10 anos. E, tendo em conta a data dos cometimentos, já se passaram mais de 20 e mais de 10 anos, logicamente".

38 STF, ADPF no 153, Plenário, relator Eros Grau, publicado no DJ de 06 de ago. de 2010

39 Trecho do voto do Ministro Ayres Brito na mencionada sessão de julgamento. 
Numa visão metajurídica, o Ministro Marco Aurélio pontuou que a anistia "É perdão, é desapego a paixões que nem sempre contribuem para o almejado avanço cultural. Anistia é ato abrangente de amor sempre calcado na busca do convívio pacífico dos cidadãos" ${ }^{40}$.

Alcançava-se, assim, aquilo que foi concebido por parte da literatura brasileira sobre o assunto como o "quarto momento" da anistia, sendo que os outros três anteriores seriam a própria aprovação da Lei da Anistia, em 1979, seguida da aprovação da Lei dos Desaparecidos, em 1995, num "segundo momento", e, então, a entrada em vigor da Lei 10.559, em 2002 como "terceiro momento". ${ }^{41}$

Pouco tempo deste acórdão o Brasil foi condenado pela Corte Interamericana de Direitos Humanos no denominado "Caso Lund" (Caso Gomes Lund E Outros ("Guerrilha Do Araguaia”) x Brasil. Sentença de 24 de novembro de 2010) quando da apreciação a um dos mais célebres casos ocorridos no período de exceção, a chamada "Guerrilha do Araguaia" cuja provocação àquele órgão jurisdicional deu-se no ano de 1995.

Recorde-se que, em 1970, um grupo de guerrilheiros do PC do $\mathrm{B}$ iniciou uma campanha na região amazônica, no rio Araguaia, com o intuito de formar um exército revolucionário no campo, seguindo as ideias de Marighela de originar a revolução do campo para depois tomar as cidades. A região era considerada estratégica devido à riqueza das suas jazidas e das proximidades.

O grupo, que nunca passou de 69 membros, realizou inicialmente um plano para conquistar a confiança dos camponeses, residindo em moradias iguais às deles e ensinando-lhes técnicas de saúde e cultivo do solo. O segundo passo era uma campanha de conscientização dos camponeses da região de treinamentos para a guerrilha. A essa altura, os militares já estavam convencidos de que as teses sobre a segurança nacional, apoiadas no combate ao "inimigo interno", eram uma realidade. Quando o SNI descobriu o foco comunista

40 Idem.

41 MEZAROBBA, Glenda. Um acerto de contas com o futuro - a anistia e suas conseqüências: um estudo do caso brasileiro. São Paulo, Humanitas/ Fapesp, 2006 
no Araguaia, em 1972, a ação militar foi típica de guerra. Cerca de 20 mil homens foram mobilizados para o local, contingente maior que o mobilizado pelas tropas brasileiras que foram para a Segunda Guerra Mundial. ${ }^{42}$

A tortura e a violência contra a população local de modo generalizado tornou quase impossível a subsistência dos guerrilheiros. $\mathrm{O}$ cerco militar, no entanto, durou mais de dois anos. Somente em 1975 o foco foi completamente massacrado, com a morte ou a prisão de todos os membros da guerrilha.

Sobre esses fatos decidiu a Corte que "a Lei de Anistia brasileira é contrária à Convenção Americana sobre Direitos Humanos, e que o Estado brasileiro é responsável internacionalmente pela interpretação e aplicação que foi dada à Lei de Anistia" ${ }^{3}$ e que "As disposições da Lei de Anistia brasileira que impedem a investigação e sanção de graves violações de direitos humanos são incompatíveis com a Convenção Americana, carecem de efeitos jurídicos e não podem seguir representando um obstáculo para a investigação dos fatos do presente caso, nem para a identificação e punição dos responsáveis, e tampouco podem ter igual ou semelhante impacto a respeito de outros casos de graves violações de direitos humanos consagrados na Convenção Americana ocorridos no Brasil".

Mais, ainda, que "O Estado descumpriu a obrigação de adequar seu direito interno à Convenção Americana sobre Direitos Humanos, contida em seu artigo 2, em relação aos artigos 8.1, 25 e 1.1 do mesmo instrumento, como consequência da interpretação e aplicação que foi dada à Lei de Anistia a respeito de graves violações de direitos humanos. Da mesma maneira, o Estado é responsável pela violação dos direitos às garantias judiciais e à proteção judicial previstos nos artigos 8.1 e 25.1 da Convenção Americana sobre

42 Sobre a inserção brasileira veja-se, entre outros, Pinheiro, Leticia. "A entrada do Brasil na Segunda Guerra Mundial.” Revista USP 26 (1995): 108-119.

${ }^{43} \mathrm{Na}$ literatura brasileira, sobre a convergência do ordenamento interno à Convenção veja-se MAZZUOLI, Valerio de Oliveira . Teoria geral do controle de convencionalidade no direito brasileiro. Revista da Ajuris, v. 113, p. 333-370, 2009. 
Direitos Humanos, em relação aos artigos 1.1 e 2 desse instrumento, pela falta de investigação dos fatos do presente caso, bem como pela falta de julgamento e sanção dos responsáveis, em prejuízo dos familiares das pessoas desaparecidas e da pessoa executada, indicados nos parágrafos 180 e 181 da presente Sentença, nos termos dos parágrafos 137 a 182 da mesma."

Por fim, "Reconhece, ainda, que o Estado brasileiro é responsável pelo desaparecimento forçado de pessoas e que deve alterar sua legislação, tipificando este delito. Enquanto esse delito não é tipificado, deve aplicar todos os mecanismos existentes no direito brasileiro para o seu julgamento e punição" e que "4. O Estado é responsável pelo desaparecimento forçado e, portanto, pela violação dos direitos ao reconhecimento da personalidade jurídica, à vida, à integridade pessoal e à liberdade pessoal, estabelecidos nos artigos 3, 4, 5 e 7 da Convenção Americana sobre Direitos Humanos, em relação com o artigo 1.1 desse instrumento, em prejuízo das pessoas indicadas no parágrafo 125 da presente Sentença, em conformidade com o exposto nos parágrafos 101 a 125 da mesma" devendo "adotar, em um prazo razoável, as medidas que sejam necessárias para tipificar o delito de desaparecimento forçado de pessoas em conformidade com os parâmetros interamericanos, nos termos do estabelecido no parágrafo 287 da presente Sentença. Enquanto cumpre com esta medida, o Estado deve adotar todas aquelas ações que garantam o efetivo julgamento, e se for o caso, a punição em relação aos fatos constitutivos de desaparecimento forçado através dos mecanismos existentes no direito interno. 3. Reconhece que o Estado brasileiro é obrigado não apenas a garantir os direitos de buscar e receber informações e à verdade, mas também a responsabilizar penalmente indivíduos que cometeram crimes" ${ }^{44}$

Em suma, o Estado (brasileiro) não poderá aplicar a Lei de Anistia em benefício dos autores, assim como nenhuma outra disposição análoga, prescrição, irretroatividade da lei penal, coisa julgada, ne bis in idem ou qualquer excludente similar de responsabilidade para eximir-se

44 Corte IDH, Caso Gomes Lund e Outros (Guerrilha do Araguaia) vs. Brasil, Exceções Preliminares, Fundo, reparação e custas, Sentença série C, no 219 , de 24 de novembro de 2010. 
dessa obrigação, nos termos dos parágrafos 171 a 179. (Parágrafo 256, $b$, sem grifo no original)

Constituía-se, assim, um claro choque de entendimentos entre os planos interno e internacional que, imediatamente, passou a ocupar a doutrina brasileira ${ }^{45}$ e estimulou o Ministério Público Federal a

"no exercício de sua atribuição constitucional de promover a persecução penal e de zelar pelo efetivo respeito dos poderes públicos aos direitos humanos assegurados na Constituição, inclusive os que constam da Convenção Americana de Direitos Humanos e que decorram das decisões da Corte Interamericana de Direitos Humanos, está vinculado, até que seja declarado inconstitucional o reconhecimento da jurisdição da Corte, ao cumprimento das obrigações de persecução criminal estabelecidas no caso Gomes Lund e outros versus Brasil”46

Tentativas de promoção da ação penal foram efetivadas empregando-se as mais variadas formas de interpretação, algumas das quais não colidindo frontalmente com o decidido pelo STF e buscando efetivar a sentença da $\mathrm{CIDH}$.

Invariavelmente, contudo, o Judiciário brasileiro bloqueia as iniciativas como se verifica na decisão de rejeição da acusação proferida pelo Magistrado Federal João César Otoni de Matos, de Marabá/ PA, empregando a lei da anistia e completando que "Pretender, depois de mais de três décadas, esquivar-se da Lei da Anistia para reabrir a discussão sobre crimes praticados no período da ditadura militar é

45 Entre outros, consulte-se GOMES, Luiz Flávio2011GOMES, Luiz Flávio; MAZZUOLI, Valerio de Oliveira . Crimes da ditadura militar e o Caso Araguaia: aplicação do direito internacional dos direitos humanos pelos juízes e tribunais brasileiros. Revista Brasileira de Direito da Comunicação Social e Liberdade de Expressão, v. 2, p. 199-234,2011. Ainda: VASCONCELOS, E. R. . A ADPF 153 e a obrigação de responsabilizar os autores de crimes nucleares: análise do caso Gomes Lund e outros (Guerrilha do Araguaia) vs. Brasil. Revista Jurídica da FA7, v. VIII, p. 000-0, 2011.

RAMOS, André Carvalho. http://www.conjur.com.br/2011-nov-24/ano-depois-sentenca-guerrilha-araguaia-nao-foi-cumprida, acessado em 14 de abril de 2013. 
equívoco que, além de desprovido de suporte legal, desconsidera as circunstâncias históricas que, num grande esforço de reconciliação nacional, levaram à sua edição" ${ }^{47}$ para lamento de parte da comunidade engajada com a persecução penal. ${ }^{48}$

Para não colidir com a lei da anistia concebeu-se, de início, a assimilação do "desaparecimento forçado" ao crime de sequestro que, crime permanente, ainda estaria em execução nada obstante a lei de reconhecimento, como mortas, das pessoas submetidas a essa prática ${ }^{49}$ o que, do ponto de vista jurídico, desnaturaria aquela figura típica sugerindo-se, ao final, abertura de investigações pontuais para verificação de cada caso concreto sobre o qual paire duvida sobre o momento da consumação delitiva. ${ }^{50}$

Fato é que os planos de enfrentamento da matéria, aquele do STF e o da CIDH parecem ser excludentes e não tendem a admitir conciliação, salvo na hipótese de se partir de uma separação espacial e funcional das tarefas de cada uma delas como propõe relevante estudo sobre o tema ${ }^{51}$ dividindo seus campos de atuação entre o controle de constitucionalidade (STF) e de convencionalidade (CIDH). Assim, a lei da anistia e a EC26 seriam "constitucionais" mas não "convencionais".

${ }^{47}$ http://www.jesocarneiro.com.br/memoria/juiz-rejeita-denuncia-contra-coronel-do-araguaia.html acessado em 20 de abril de 2013.

48 A respeito, http://www.conectas.org/institucional/judiciario-brasileiro-tem-a-obrigacao-de-processar-crimes-permanentes-da-ditadura acessado em 20 de abril de 2013.

49 Vide tópico 3.1.1, supra.

50 VASCONCELOS, E. R. . A investigação penal dos crimes de seqüestro, homicídio e ocultação de cadáver na guerrilha do araguaia: uma conciliação parcial entre a ADPF 153 do STF e o caso gomes Lund vs. Brasil da corte IDH. Revista Acadêmica da Escola Superior do Ministério Público do Estado do Ceará, v. III, p. 001-017, 2011.

51 RAMOS, André de Carvalho. Crimes da Ditadura Militar: A ADPF 153 e a Corte Interamericana de Direitos Humanos. In GOMES, Luiz Flávio et al. Crimes da ditadura militar: uma análise à luz da jurisprudência atual da Corte Interamericana de Direitos Humanos: Argentina, Brasil, Chile, Uruguai. SP, RT, 2011, p. 219 
E, no campo penal, tende-se a assimilar a primeira como fonte de impunidade e negação dos compromissos internacionais assumidos pelo Brasil com todas as suas consequências, enquanto a segunda revela-se como instrumento de resgate da punição justa e didaticamente adequada a demonstrar toda a supremacia dos direitos humanos.

Para os fins deste trabalho assume-se que a anistia bilateral construída na transição política é incompatível com a ordem constitucional que tem, em seu bojo, os tratados e convenções internacionais que versam sobre direitos humanos como decorrência dos objetivos da República brasileira. ${ }^{52}$ Igualmente, não se afigura sustentável diante da própria ordem internacional que, se olhada isoladamente, deve se projetar para o direito interno (diante dos compromissos jurídicos e políticos assumidos pelo Brasil) de modo a compelir o Estado brasileiro a dar eficácia plena a tudo quanto pactuado em termos de proteção aos direitos humanos e fundamentais.

52 Há, a partir deste aspecto, um problema nuclear para o constitucionalismo brasileiro, o da própria dimensão da extensão do poder constituinte, dado que a EC mencionada foi, formalmente, o ponto de partida para a reconstrução constitucional de 1988. A esse respeito, JÚNIOR, Tércio Sampaio Ferraz. Constituinte: assembléia, processo, poder. Editora Revista dos Tribunais, 1985. Destaca-se, por oportuno nessa obra que "A noção de poder originário só é válida num sentido formal. Nenhum poder é, de fato, completamente inicial, autônomo e incondicionado. E a sua legitimidade, embora sempre invocada, até mesmo quando ditatorial o poder, não dispensa uma discussão de seus fundamentos. Não é completamente inicial porque o poder é sempre um conjunto de relações entre diversas forças sociais e só formalmente se pode determinar uma delas como o poder de onde derivam os demais poderes. Não é completamente autônomo porque, não só pela aceitação de limitações de ordem social, histórica, cultural, econômica, ideological etc., ele já vem restringido. Não é completamente incondicionado porque não só freqüentemente já recebe prefixadas certas diretrizes básicas, como sobretudo porque tem de atuar e deliberar conforme certas regras que antecedem sua manifestação (p. 23). Décadas depois o assunto continuaria em pauta, ainda que com um vies distinto daquele prioritário para este texto: BERCOVICI, Gilberto. O poder constituinte do povo no Brasil: um roteiro de pesquisa sobre a crise constituinte. Lua Nova: Revista de Cultura e Política, n. 88, p. 305-325, 2013. 
A decisão da Corte, contudo, possui reflexos jurídicos que se voltam prioritariamente para o Poder Executivo ${ }^{53}$. Mas deve ser recordado que o STF, por sua vez, quando da apreciação da ADPF, decidiu com "eficácia contra todos e efeito vinculante relativamente aos demais órgãos do Poder Público" ${ }^{54}$. É, por via obliqua, mais uma forma de controle concentrado de constitucionalidade com eficácia "erga omnes".

O efetivo cerne de dificuldade de conciliar o controle de convencionalidade com o direito interno dá-se quando a CIDH determina que "...nenhuma outra disposição análoga, prescrição, irretroatividade da lei penal, coisa julgada, ne bis in idem ou qualquer excludente similar de responsabilidade para eximir-se dessa obrigação..." posto que transita por uma seara do próprio Estado de Direito que se quer consolidar no direito interno ${ }^{55}$ onde a rejeição da regra da anterioridade da lei penal e da prescrição aparecem em grau constitucional e no mesmo patamar que as normas regentes dos objetivos da República.

A situação é ainda mais acentuada porque mesmo no plano internacional inúmeras as convenções, como aquela sobre desaparecimento forçado de pessoas, seja no âmbito da ONU, seja no espaço da OEA são tardias ao extremo em relação ao próprio momento de encerramento - ainda que formal - do regime caído.

Aponte-se que em 1994, foi realizada, em Belém (PA), Assembleia Geral da OEA quando se deu a criação da Convenção

${ }^{53}$ Neste sentido é que deve ser entendida a conclusão de prestigiosa doutrina quando afirma que "O Brasil tem a obrigação de cumprir a decisão da Corte Interarmericana de Direitos Humanos... [com] o dever de investigar e, se for o caso, proferir os referidos delitos contra a humanidade...". GOMES e MAZZOULI. Crime da Didadura militar e o "Caso Araguaia": aplicação do direito internacional dos direitos humanos pelos juizes e tribunais brasileiro". In GOMES, Luiz Flávio et al. Crimes da ditadura militar: uma análise à luz da jurisprudência atual da Corte Interamericana de Direitos Humanos: Argentina, Brasil, Chile, Uruguai. SP, RT, 2011.p. 72.

${ }_{54}$ Art. 10, § 3o da lei n. 9.882.

55 A propósito dessa relação veja-se, entre outros, MCADAMS, James A., (Ed.). 1997. Transitional Justice and the Rule of Law in New Democracies. Notre Dame, IN: University of Notre Dame Press. 
Interamericana sobre o Desaparecimento Forçado de Pessoas, assinada imediatamente que foi pelo Brasil ${ }^{56}$. Ela define o "desaparecimento forçado" a privação de liberdade de pessoas, praticada por agentes estatais ou por grupos ou pessoas com autorização, apoio ou consentimento do Estado. Apenas em 2008 o Congresso Nacional aprovou o Projeto de Decreto Legislativo no 116 , de 2008.

Mais ainda, há texto internacional nuclear para o assunto posto que toca no tema da imprescritibilidade dos crimes de guerra e dos crimes contra humanidade, cabendo recordar que

Em 26 de novembro de 1968, a Assembleia Geral das Nações Unidas, pela Resolução no 2.391 (XXIII), aprovou o texto de uma Convenção sobre a imprescritibilidade dos crimes de guerra e dos crimes contra a humanidade, declarando que estes últimos compreendem, além do genocídio, também os atos de apartheid, ainda que tais atos não sejam definidos como crimes pelas leis internas dos Estados onde foram perpetrados. Vergonhosamente, - Brasil não assinou originariamente a Convenção, nem a ela aderiu.57 (sem grifo no original).

O cenário das disposições persecutórias penais exigiria a punição por crimes que não existiam no cenário internacional à época dos fatos ou outros que, no caso brasileiro, sequer foram aderidos em sua totalidade.

A eventual invocação de um direito internacional consuetudinário que permitisse a punição e julgamento tal como se justificou ao final da II Guerra Mundial seria de aplicabilidade igualmente duvidosa no plano interno e restaria a possibilidade também extremamente questionável de estender a tipificação dos crimes de guerra

56 O texto da convenção já foi ratificado pela Argentina, Bolívia, Colômbia, Costa Rica, Guatemala, Peru, Hoduras, México, Equador, Panamá, Paraguai, Uruguai e Venezuela

57 COMPARATO, Fábio Konder. TORTURA, p. 80. In http://portal. sdh.gov.br/acessoainformacao/acoes-e-programas/Publicacao\%20-\%20 TORTURA.pdf\#page $=80$ 
como internacionalmente considerados aos fatos do direito interno ${ }^{58}$ naquilo que foram tipificados no Estatuto de Roma, este em vigor no direito interno brasileiro.

Aqui remanesce outro desdobramento. As normas que criam tipos penais no cenário internacional, mesmo que entronizados no cenário jurídico local exigem a tipificação pelo processo legislativo do direito interno e não são automaticamente aplicáveis a partir do exterior para o interior. Em última análise, portanto, o principio da complementariedade do Estatuto de Roma chama a atividade do legislador nacional sob o risco de desamparar os nacionais da jurisdição de seu próprio pais por deficiência do direito material.

Restaria de todo o cenário jurídico, caso se queira afirmar a imperiosa necessidade da efetivação da sentença da CIDH no seu dispositivo penal em nome de todos os postulados já mencionados, o crime de tortura nos termos da Lei 9455 de 1997, desprezada, por certo, nos termos daquele decisum, qualquer referência à prescrição e anterioridade da lei penal. Neste caso não deixaria de ser irônico que a defesa do estado de direito e da dignidade da pessoa humana fosse feita com o desprezo a duas regras basilares do primado da lei e de garantia ao ser humano contra os arbítrios do Estado.

O desafio é, contudo, não deixar que seja esvaziado o diálogo entre os sistemas e as Cortes de modo a não estimular, no seio da sociedade civil como um todo e no meio jurídico em particular, a possibilidade de que o Estado brasileiro possa, pura e simplesmente, ignorar o teor da condenação que lhe recaiu. E fazer isso de modo a, minimamente, manter as bases de um sistema persecutório condizente com o estado de direito.

58 Theodor Meron. International Criminalization of Internal Atrocities The American Journal of International Law, Vol. 89, No. 3 (Jul., 1995), pp. 554-577 


\section{REFERÊNCIAS BIBLIOGRÁFICAS}

BAL, Mieke, Jonathan Crewe, and Leo Spitzer, eds. 1999. Acts of Memory: Cultural Recall in the Present. Hanover, NH: University Press of New England.

BARAHONA DE BRITO, Alexandra, 'The Long and Tortuous Path to Military Amnesty and the Referendum in Uruguay, 1985-1989' in Barahona de Brito, Alexandra (ed), Human Rights and Democratization in Latin America: Uruguay and Chile (Oxford University Press, Oxford 1997)

BARAHONA de Brito, Alexandra, GONZÁLEZ-ENRÍQUEZ Carmen, and Aguilar, PALOMA, eds. 2001. The Politics of Memory: Transitional Justice in Democratizing Societies. New York, NY: Oxford University Press;

BARTHEL, Diane L. 1996. Historic Preservation: Collective Memory and Historical Identity. New Brunswick, NJ: Rutgers University Press.

BASSIOUNI, M. Cherif. 2002. Universal Jurisdiction for International Crimes: Historical Perspectives and Contemporary Practice. In Post-Conflict Justice, edited by M. C. Bassiouni. Ardsley, NY: Transnational Publishers.

BATISTA, C. K. L.; GITAHY, R. R. C. . O direito à memória e à verdade e sua difusão virtual: tecnologia e saberes sociais aliados na preservação da história. In: Alessandro Martins Prado; Claudia Karina Ladeia Batista; Isael Jose Santana. (Org.). Direito à Memória e à Verdade e Justiça de Transição no Brasil: uma história inacabada! Uma República Inacabada. 1ed.Curitiba: CRV, 2011 , v. 1 , p. $89-100$.

BERCOVICI, Gilberto. O poder constituinte do povo no Brasil: um roteiro de pesquisa sobre a crise constituinte. Lua Nova: Revista de Cultura e Política, n. 88, p. 305-325, 2013.

BOBBIO, Norberto. A era dos direitos. Rio de Janeiro: Campus, 1992. p. 28

BRASIL . Direito à memória e à verdade: seminário [recurso eletrônico]. Brasília: Câmara dos Deputados, Edições Câmara, 2012.166 p. - (Série ação parlamentar; n. 433) Seminário realizado pela Comissão de Direitos Humanos e Minorias da Câmara dos Deputados em 2009. ISBN 978-85-736-5953-5

CANÇADO TRINDADE A.A., El Desarrollo del Derecho Internacional de los Derechos Humanos Mediante el Funcionamiento y la Jurisprudencia de la Corte Europea y la Corte Interamericana de Derechos Humanos, CtIADH, San José of Costa Rica, 2007, pp. 1-75; 
CANÇADO TRINDADE V.F.D., 'Uma Análise das Leis de Auto-Anistia na Evolução Jurisprudencial da Corte Interamericana de Direitos Humanos', 8 Revista do Instituto Brasileiro de Direitos Humanos (2008) pp. 281-91.

COLE, Elizabeth A. 2007. Transitional Justice and the Reform of History Education. International Journal of Transitional Justice 1 (1):115-137.

COMPARATO, Fábio Konder. TORTURA, p. 80. In http://portal.sdh.gov. br/acessoainformacao/acoes-e-programas/Publicacao\%20-\%20TORTURA. pdf\#page $=80$

D’ARAUJO, Maria Celina Soares . O estável poder de veto Forças Armadas sobre o tema da anistia política no Brasil. Varia História (UFMG. Impresso), v. 28 , p. 573-597, 2012 o

DELMAS-MARTY,Mireille."La responsabilité pénale en échec (prescription, amnistie, immunités).” Antonio Cassese et Mireille Delmas-Marty (éds.), Juridictions nationales et crimes internationaux, PUF (2002): 637.

DINIZ, Eli. A transição política no Brasil. Uma reavaliação da dinâmica da Abertura. Dados, Rio de Janeiro, v. 28, n. 3, p. 329-346, 1985.

DISSENHA, Rui Carlo. "Anistias Como Prática do Direito Internacional Criminal ea Complementaridade do Tribunal Penal Internacional." Revista Brasileira de Direito Internacional-RBDI 1.1 (2006).

ESER, Albin. "For universal jurisdiction: against Fletcher's antagonism." Tulsa L. Rev. 39 (2003): 955.) MEINTJES, Garth, and Juan E. Méndez. 2000. Reconciling Amnesties with Universal Jurisdiction. International Law FORUM du Droit International 2 (2):76-97

GABEIRA, Fernando. Carta sobre a anistia: a entrevista do Pasquim. Rio de Janeiro,: Codecri, 1979.

GOMES, L. F. e MAZZOULI, V. Crime da Didadura militar e o "Caso Araguaia": aplicação do direito internacional dos direitos humanos pelos juizes e tribunais brasileiro". In GOMES, Luiz Flávio et al. Crimes da ditadura militar: uma análise à luz da jurisprudência atual da Corte Interamericana de Direitos

GOMES, Luiz Flávio2011GOMES, Luiz Flávio; MAZZUOLI, Valerio de Oliveira . Crimes da ditadura militar e o Caso Araguaia: aplicação do direito internacional dos direitos humanos pelos juízes e tribunais brasileiros. Revista Brasileira de Direito da Comunicação Social e Liberdade de Expressão, v. 2, p. 199-234, 2011. 
GONZÁLEZ GONZÁLEZ, José Luis and Pablo Galain Palermo, 'Uruguay' in Ambos, Kai, Ezequiel Malarino and Gisela Elsner (eds), Jurisprudencia Latinoamericana Sobre Derecho Penal Internacional (Konrad-AdenauerStiftung, Berlin 2008)

HELMKE, G., Courts Under Constraints: Judges, Generals, and Presidents in Argentina (Cambridge University Press, 2005)

HUYSE, Luc. 2001. “Amnesty, Truth, or Prosecution?” In Reychler, Luc and Thania Paffenholz, Peace-building: A Field Guide. Boulder, CO: Lynne Rienner Publishers.

JÚNIOR, Tércio Sampaio Ferraz. Constituinte: assembléia, processo, poder. Editora Revista dos Tribunais, 1985.

KAMMINGA, Menno T. 2001. Lessons Learned from the Exercise of Universal Jurisdiction in Respect of Gross Human Rights Offenses. Human Rights Quarterly 23 (4):940-974.

LEAL Rogério Gesta. A Memória Como Direito Fundamental Civil E Político: Qual O Caminho Brasileiro? In Verdade, memória e justiça [recurso eletrônico]: um debate necessário/ Rogério Gesta Leal organizador. - Santa Cruz do Sul: EDUNISC, 2012.. páginas 08/34.

LEMOS, Maitê Damé Teixeira.; LEAL, M. C. H. . O controle jurisdicional de políticas públicas no âmbito da verdade, justiça e reconciliação: um caminho entre o ativismo e a efetiva proteção dos direitos humanos. In: Rogério Gesta Leal. (Org.). Verdade, memória e justiça: um debate necessário. 1ed.Santa Cruz do Sul: EDUNISC, 2012, v., p. 35-58

LEMOS, Renato. Anistia e crise política no Brasil pós-1964. Topoi, Rio de Janeiro, n. 5, p. 287-313, set. 2002.

LUTZ, Ellen e SIKKINK, Kathryn. 2001. The Justice Cascade: The Evolution and Impact of Foreign Human Rights Trials in Latin America. Chicago Journal of International Law 2 (1):1-34.

LUTZ, Ellen L., 'Responses to Amnesties by the Inter-American System for the Protection of Human Rights' in Harris, David J. and Stephen Livingstone (eds), The Inter-American System of Human Rights (Clarendon Press, Oxford 1998);

MALLINDER, Louise. "Amnesties' Challenge to the Global Accountability Norm? Interpreting Regional and International Trends in Amnesty Enactment." (2012): 69-96. 
MAZZUOLI, Valerio de Oliveira. Teoria geral do controle de convencionalidade no direito brasileiro. Revista da Ajuris, v. 113, p. 333-370, 2009.

McADAMS, James A., (Ed.). 1997. Transitional Justice and the Rule of Law in New Democracies. Notre Dame, IN: University of Notre Dame Press.

MEINTJES, Garth. 2000. Domestic Amnesties and International Accountability. In International Crimes, Peace, and Human Rights: The Role of the International Criminal Court, edited by D. L. Shelton. Ardsley, NY: Transnational Publishers

MÉNDEZ, Juan E. and Javier Mariezcurrena, 'Accountability for Past Human Rights Violations: Contributions of the Inter-American Organs of Protection' (1999) 26(4) Crime \& Soc Just Associates 84;

MERON, Theodor. International Criminalization of Internal Atrocities The American Journal of International Law, Vol. 89, No. 3 (Jul., 1995), pp. 554-577

MEZAROBBA, Glenda. O preço do esquecimento: as reparações pagas às vítimas do regime militar (uma comparação entre Brasil, Argentina e Chile). Tese. Faculdade de Filosofia, Letras e Ciências Humanas, Universidade de São Paulo (USP). São Paulo, 2008.

MEZAROBBA, Glenda. Um acerto de contas com o futuro - a anistia e suas conseqüências: um estudo do caso brasileiro. São Paulo, Humanitas/Fapesp, 2006

NINO, Carlos Santiago, Radical Evil on Trial (Yale University Press, New Haven 1996);

Oliveira Fabiana Luci de . O Supremo Tribunal Federal no processo de transição democrática: uma análise de conteúdo dos jornais Folha De S. Paulo e O Estado De S. Paulo. Rev. Sociol. Polít., Curitiba, 22, p. 101-118, jun. 2004.

OLIVEIRA, A.J.; LIMA, A. D.; Prado, A.L.; Silva, E.M.M.; Afonso, A.M.O.; Batista,C.K.L.; GITAHY, R. R. C.;ARAUJO,D.A.C.;Araújo,E.L..Memória E Verdade Com Um Direito Absoluto E Inalienável Independentemente Das Forças Do Poder.. In: Alessandro Martins do Prado; Cláudia Karina Ladeia Batista; Isael José Santana. (Org.). Direito à memória e à verdade e justiça de transição no Brasil Uma história inacabada! Uma República inacabada. 1ed. Curitiba-PR: CRV, 2011, v., p. 43-54. 
Pinheiro, Leticia. "A entrada do Brasil na Segunda Guerra Mundial." Revista USP 26 (1995): 108-119.

PIOVESAN, Flávia. Princípio da Complementaridade e Soberania. Revista CEJ, Brasília, no 11, p. 71-74, 2000.

PLAZZA, Rosimary e PRIORI Angelo. O ensino de história durante a ditadura militar. II Encontro de Pesquisa em Educação, 2007, Maringá. Anais do II Encontro de Pesquisa em Educação.. Maringá: UEM-DTP, 2007. v. 1. p. 1-9.

RAMOS, André Carvalho. http://www.conjur.com.br/2011-nov-24/anodepois-sentenca-guerrilha-araguaia-nao-foi-cumprida, acessado em 14 de abril de 2013.

RAMOS, André de Carvalho. Crimes da Ditadura Militar: A ADPF 153 e a Corte Interamericana de Direitos Humanos. In GOMES, Luiz Flávio et al. Crimes da ditadura militar: uma análise à luz da jurisprudência atual da Corte Interamericana de Direitos Humanos: Argentina, Brasil, Chile, Uruguai. SP, RT, 2011, p. 219

RATNER, Steven R. and Jason S. Abrams. 1997. Accountability for Human Rights Atrocities in International Law: Beyond the Nuremberg Legacy. New York: Oxford University Press.

REIS, Thiago Felipe dos, e PRADO, Eliane Mimesse. Entre a teoria e a prática: a ditadura militar brasileira em manuais didáticos da educação básica Anais Eletrônicos do IX Encontro Nacional dos Pesquisadores do Ensino de História 18, 19 e 20 de abril de 2011- Florianópolis/SC . In: IX Encontro Nacional dos pesquisadores do Ensino de História: América latina em perspectiva: culturas, memórias e saberes, 2011, Florianópolis. Caderno de Resumos. Florianópolis: Imprensa Universitária, 2011.v. 1. p. 97.

ROEHRIG, Terence, The Prosecution of Former Military Leaders in Newly Democratic Nations: The Cases of Argentina, Greece, and South Korea (McFarland \& Company Inc Publishers, Jefferson, NC 2002) BAKKER, Christine A. E., 'The Full Stop to Amnesty in Argentina: The Simón Case' (2005) 3(5) J Int'L Crim Just 1106

ROHT-ARRIAZA, Naomi, (Ed.). 1995. Impunity and Human Rights in International Law and Practice. New York: Oxford University Press. Ainda: Chigara, Ben. 2002. Amnesty in International Law: The Legality under International Law of National Amnesty Laws. Harlow, UK: Longman e 
Mallinder, Louise. 2008. Amnesty, Human Rights and Political Transitions: Bridging the Peace and Justice Divide. Oxford, UK: Hart Publishing.

SCALABRINO M., Per Non Dimenticare - Violazioni dei Diritti Umani e Leggi di Amnistia in America Latina, Milano, Vita e Pensiero (V\&P), 2007, pp. 93-145 and 169-213;

URUGUAI . Servicio Paz y Justicia, Uruguay Nunca Más: Human Rights Violations, 1972-1985 (Temple University Press, Philadelphia 1992)

VASCONCELOS, E. R. . A ADPF 153 e a obrigação de responsabilizar os autores de crimes nucleares: análise do caso Gomes Lund e outros (Guerrilha do Araguaia) vs. Brasil. Revista Jurídica da FA7, v. VIII, p. 000-0, 2011.

VASCONCELOS, E. R. . A investigação penal dos crimes de seqüestro, homicídio e ocultação de cadáver na guerrilha do araguaia: uma conciliação parcial entre a ADPF 153 do STF e o caso gomes Lund vs. Brasil da corte IDH. Revista Acadêmica da Escola Superior do Ministério Público do Estado do Ceará, v. III, p. 001-017, 2011.

VILLEY, Michel. O direito e os direitos humanos. SP: Martins Fontes, 2007.p. 17

VINUESA, Raúl Emilio, 'Direct Applicability of Human Rights Conventions within the Internal Legal Order: The Situation in Argentina' in Conforti, Benedetto and Francesco Francioni (eds), Enforcing International Human Rights in Domestic Courts (International Studies in Human Rights, Vol. 49, Martinus Nijhoff Publishers, Hague 1997).

\section{COMO CITAR ESTE ARTIGo:}

CHOUKR, Fauzi Hassan. Diálogos possíveis entre o Supremo Tribunal Federal e a Corte Interamericana de Direitos Humanos no "Caso Araguaia": uma defesa ampla, geral e irrestrita dos direitos humanos? Revista Brasileira de Direito Processual Penal, Porto Alegre, vol. 2, n. 1, p. 269 - 299, 2016. http://dx.doi.org/10.22197/rbdpp.v2i1.24 